\title{
Identification of lineaments using Google tools
}

\author{
N Rana, CP Chakravarthy and R Nair \\ Heavy Civil Infrastructure, L\&T Construction, \\ Chennai, India \\ ns-rana@lntecc.com
}

\author{
L Gopi Kannan \\ Engineers India Limited (EIL) \\ Chennai, India
}

\begin{abstract}
Recent advances in data acquisition technologies, have led to a growing interest in capturing high resolution rock surface images, Digital geologic maps that use a virtual globe interface, like google earth are a relatively new medium for presenting geologic data and interpretations. Models viewed in google earth are more intuitive for visualizing 3-D geological structures than traditional paper maps. Google earth displays satellite images of varying resolution of the earth's surface, allowing us to see things looking perpendicularly down or at an oblique angle, with perspective. Geological lineaments represent the intersection between discontinuity planes and an observation surface. Lineament identification plays key role in an underground project in all phases of the investigations and construction stages. Lineaments perceived in google earth images are reliable indicators of geologic structure. For identification of lineaments, google earth images technique is the most effective tool in conjunction with ground truth and toposheet for collection of spatial information and very useful in identification and mapping of the lineaments of an area. Structural geology studies, geologic lineaments and their pattern information are essential for better planning and timely execution of projects to avoid any hazards, google earth images provide lineament information.
\end{abstract}

The present work deals with the integration of satellite imagery and surface geological data to improve the structural knowledge of any project. In this paper outline a methodology that allows efficient mapping for identification of geologic features and lineaments using google earth image of the rock surface in various phases of a project. In this paper also provides techniques to generate and display 2D and 3D geological data in google earth, oriented 2D and 3D geological symbols based on outcrop data and contour creation are covered. CAD Software such as SketchUp is used to generate the structural symbols for mapping ground based structures in google earth and to convert graphic images files of 2D into 3D Collada object models that are capable of being stretched, oriented and rotated in google earth for display in profile view. Excel worksheets are used to generate KML scripts for the structural symbology and well field visualization.

A interactive google earth geologic map was built in various stages of an underground project, this technique described with a case study, this covers the use of google earth tools in different stages of a project, in pre-investigation/desk study stage identify the lineaments using google earth and find out the outcrop \& co- ordinates for surface mapping and generate contour map using SketchUp. During detail investigation stage, assign joint orientation in google earth and developed a predictive lineament trend map to better interpretation of the geologic features for construction. During construction stage, back analysis this predictive lineament trend map with actual structural geologicalmap of the project then predicted lineament trend map (generated using google earth tools) are compared against actual structural geological map \& structural map can be optimised for further excavation. This map was produced in very short time, this shows the potential of using this method for predicted and efficient mapping of geological structures, particularly from remote, inaccessible or hazardous sites. Further an attempt has been made for mapping of lineaments and knowledge base preparation using google earth techniques for part of the proposed project site. Categorized the identified lineaments and geologic structures as per their features and projected these features for future projection nearby. This methodology might potentially be adopted for the identification of several features of geological origin. Applications such as identifying suitable site for dams, reservoirs and underground structure facility, and finding potential risks associated with the proposed area of layout etc.

Keywords-Lineaments; Google earth; Sketch Up; Geological investigations

\section{INTRODUCTION}

Google Earth is a useful interactive mapping tool that allows users to control oblique perspective views of the earth. This perspective view makes it possible to blend three- dimensional features of the earth's surface with traditional two dimensional map space. Knowledge of geological structures and their topological relationship (e.g., fault, folds, joints/shears, dykes etc.) is important for a wide range of geoscience research and underground construction. Possibly the most basic dataset used to capture information on geological structures is the geological map. Structural maps typically show the location, geometry, orientation and trace length of structures of interest. Further information typically captured may also include across-strike spacing, roughness and density The most fundamental of these properties are location, surface geometry and orientation because these properties are critical components of widely used techniques such as two dimensional (2D) cross-section construction, cross section balancing, three dimensional (3D) visualisation of geology and modelling of geophysical data. Such approaches can generate abundant and high quality data but can take weeks, even months, to complete.

In this paper outline a structural trend interpretation technique that allows efficient trend mapping of geological lineaments using google earth and CAD tools of the proposed project site. This method harnesses use of google 
earth in the various stages of a project. Geological lineaments are first identified and delineated in the google earth, assign orientation of the geological structures (faults, joints, shears, fractures) in google earth (using data from geological surface mapping and borehole data) and then import google image in the CAD tools and verified with the actual structural data and interpret the structural trend map w.r.t tunnel alignment and topography obtained from google earth.

\section{PURPOSE}

This document aimed to prepare procedure for the identification of lineament and fracture trend map of proposed project using google earth tools and relate them to structural and tectonic influences. It is mapped the intensity and orientations of faults/ fractures/joints in the selected area The purpose of this document is to develop a procedure for identification of the geological structures in the proposed project site using google earth and:

- To identify geological structures for desk study for a proposed project site using google earth \& CAD tools

- Prepare predictive structural trend map using identified geological structures by google earth and geological site investigation data (surface geological mapping and borehole data)

- Verification and delineation of the prediction structural trend map and compare with the actual structural geologic map during construction \& applying the impression identified \& verified to similar projects with improved predictability.

\section{MAPPING BY DigITAL ANALYSIS}

The advent of Web-based global digital elevation model (DEM) databases (Google Earth, NASA World Wind), which have put virtual 3-D terrains at the fingertips of the novice user. These software packages are freely available, with intuitive, easy-to-use interfaces that only require a computer with high-speed Internet access. Digital topographic maps were tested for applicability to register regional geological structures [7]. The digital topographic data is combined with other digital data such as satellite- or aerial photos and maps. By processing these data it is possible to locate lineaments that may represent rock boundaries, weakness zones or faults. High local groundwater flow into rock tunnels may lead to a potential hazard and is an important factor influencing construction time and costs. Geological features such as fault zones and open fractures can be the source of very high local groundwater inflows $[1,4]$. Having a reliable estimation of location groundwater inflows is essential before excavation of tunnels. To reduce the costs and time of field works, google earth image interpretation can be a good solution.

Ground overlays are an effective display and presentation tool, but they don't encourage much interaction or inquiry from the user. To achieve the full potential of virtual globes as an interactive, inquiry-driven resource, we have developed a methodology for the presentation of geologic maps within Google Earth that goes beyond traditional 2-D imagery. Principal components of these maps include[10].

- Units and contacts as individually selectable objects that can be turned on and off;

- Floating orientation symbols that show strike and dip or trend and plunge in the proper 3-D orientation at the precise location where measured in the field;

- Field data, such as outcrop photos or biostratigraphic information, as clickable objects linked to their field locations;

- Map legends as screen overlays.

\section{DATA ACQUISITION}

Google Earth images in many places in the world show bedrock with strong, contrasting colors in areas with little vegetation to obscure contacts and unit relationships. Imagery is seamless, and, in many areas of the world, the level of detail is amazing.

To encourage access to these data we use Google Earth, Google SketchUp and Microsoft excel for Keyhole Markup Language (KML) script and to deliver CAD tools derived visualizations of these data for the verification of predicted structural trend map (using google earth and CAD tools) with actual structural map (developed during site investigation and construction) purposes. Google earth used to $3 \mathrm{D}$ visualisation of the project site and to identification and delineation of the geological structures/lineaments, and to explain the orientation symbols planes of the geological structures (faults, folds, joints, shears) which are collected from the geological site investigations and during underground construction. Google SketchUp used to generate contour map of the study area and to detect and interpret the contour edges and find out the structural/lineament trends and verify with the model developed by google earth [5]. Microsoft excel used to contain the geological information (joint orientation and type of features) and co-ordinates of the geological features to create script for the KML file. KML is primarily responsible for the versatility of Google Earth as an effective medium for interactive presentation of geospatial data. This is accentuated when combined with COLLADA, an XML-based scripting language incorporated within Google's SketchUp program that allows users to include 3D models within Google Earth. This is the method we use to model structural map symbols as 3-D models, which are exported to specific locations and orientations within Google Earth. And finally Auto Cad used to verify the predicted structural trend map to actual structural map by using the google earth image and interpreted contour image with overlay of the project layout and the structural map of the project site.

\section{OVERVIEW OF WORKFLOW}

Our workflow consists of various steps on the basis of various stages of the projects as shown in Fig. 1. Firstly for desk study stage, we identified and marked geological structures/lineaments using google earth image and analysis of the photographic dataset and create contour of the proposed project area and detect the contour edges identified the trend of the detected lines using CAD tools. Secondly, 
use the geological surface mapping and borehole data collected during detailed geological site investigation and assign these geological orientation symbols in the google earth using Microsoft excel and convert into KML script, and the best-fit plane coefficients are computed then analyse the structural trends and developed the predicted structural trend map of the proposed project site. Finally verify the predicted structural trend map with the actual structural map which is developed during construction stage. In the following flow chart show the process of adopting \& evaluating this system proposed.

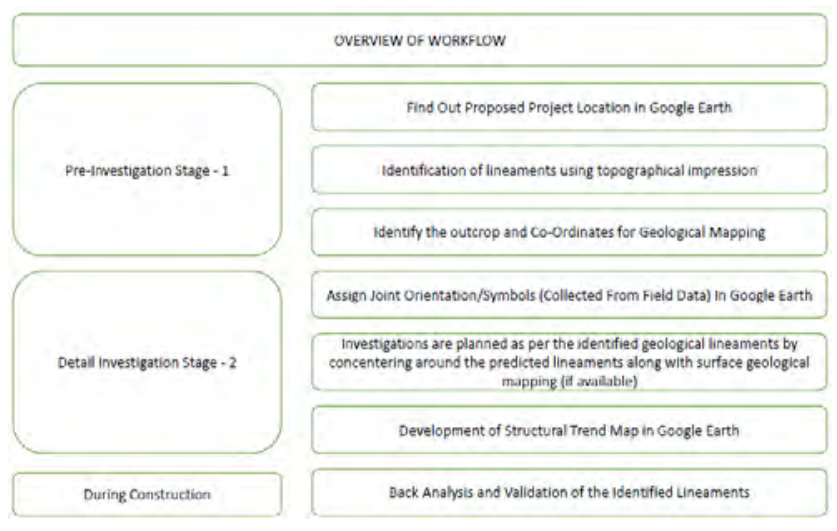

Fig. 1 Overview of workflow

\section{BuILding a GoOgLe EARTh InTERACTIVE GeOlogic MaP IN VARIOUS STAGES OF A UNDERGROUND PROJECT}

Google Earth satellite images in many places in the world show bedrock with strong, contrasting colors in areas with little vegetation to obscure contacts and unit relationships. Imagery is seamless, and, in many areas of the world, the level of detail is amazing [6]. Google earth images and CAD tools are used to identify the geological structure/ lineaments in various stages of the underground projects.

\section{A. Pre-Investigation Stage/Desk Study}

Site investigations in general require topographic and geologic considerations. Google earth images data can be used for such assessment. In case of site investigation for civil engineering projects, information on topography is essential. Geological consideration involves the different soil and rock types and physical properties. The hydro geological and geomorphologic information along with geological structures derived from google earth data are very useful in sitting the ground water bore holes.

\section{1) Find out proposed project location in google earth:}

There are numerous advantages to integrating Google Earth (GE) into the upper division geology curriculum including it has the ability to show map areas, landforms and geologic hazards from multiple perspectives in 3-D; latitude and longitude coordinates may be quickly determined for a particular geologic feature; geologic, geomorphic, natural hazard or other information may be applied to a base map. It allows for Google searches for topographic features and locations; one may setup customizable tours of geomorphic features and natural hazards anywhere in the world

To understand the geological consideration of a proposed project site need to desk study of the regional and local geological structures of the area, for this we need to find out the project location view in Google earth, by knowing the name of the location use the coordinates of the project site (if available) fig. 2. Shown a proposed project site location in google earth image.

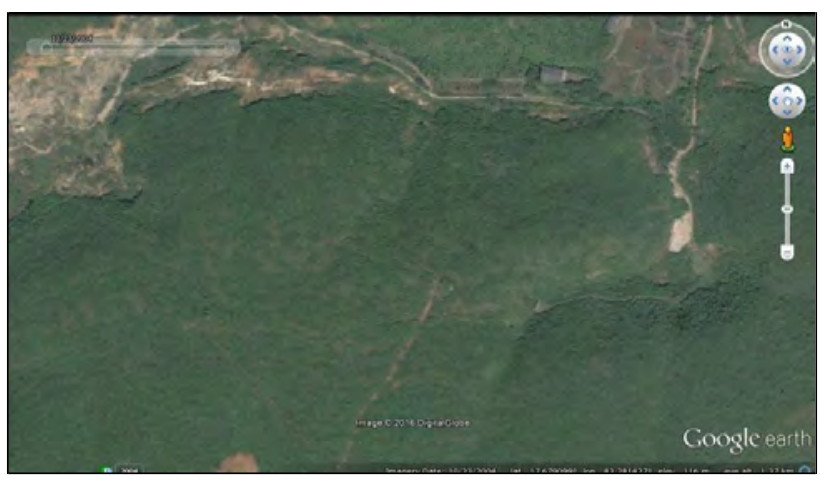

Fig. 2 Google earth image of the project site

\section{2) oIdentify the outcrop and co-ordinates for geological mapping:}

A linear characteristic of a superficial parameter genetically related to a structural, stratigraphic, sedimentary, geochemical or to a combination of these factors is a "lineament". The way lineaments reflect structures depends on the exposure degree of the affected rock. In areas not covered by recent deposits, lineaments directly reflect structures since lineaments are the intersection between planes of discontinuity with the surface. The relationship between lineaments and structures in regions covered by recent deposits may be more complex. Without neotectonics, covered structures can control both the predepositional topography and the location of fluids affecting deposits. Both the original materials and its subsequent affectation have the potential to print linear signals to the surface.

Using google earth images we can identify the outcrops for mapping and the locations for traversing the geological features by using $2 \mathrm{D}$ and $3 \mathrm{D}$ view and by rotating the images with different angles and closer view by zooming the object of the selected area. With rotating the image we can identify the river cut, road cut and other rock surface outcrop which can help to identify the geological setting of the areas, and also provide the co-ordinates of these selected outcrops, which may helpful during field geological investigation, geological impression to by observing the topography.

\section{3) Identification and delineation of lineaments:}

Bodies of water, rivers, lakes, and oceans, are often the simplest features to identify because they tend to have unique shapes and they show up on maps. Other obvious patterns come from the way people use the land. When people cut down a forest, the clearing is often square or has a series of herring-bone lines that form along roads. A 
straight line anywhere in an image is almost certainly human-made, and may be a road, a canal, or some kind of boundary made visible by land use.

Geology shapes the landscape in ways that are often easier to see in a google image. Volcanoes and craters are circular, and mountain ranges tend to run in long, sometimes wavy lines. Geologic features create visible textures. Canyons are squiggly lines framed by shadows. Mountains look like wrinkles or bumps. These features can also affect clouds by influencing the flow of air in the atmosphere. Mountains force air up, where it cools and forms clouds. Islands create turbulence that results in swirling vortices or wakes in the clouds. When you see a line of clouds or vortices, they provide a clue about the topography of the land below. Occasionally, shadows can make it hard to tell the difference between mountains and canyons. This optical illusion is called relief inversion. It happens because most of us expect an image to be lit from the top left corner. When the sunlight comes from another angle (especially from the lower edge), the shadows fall in ways we don't expect and our brains turn valleys into mountains to compensate. The problem is usually resolved by rotating the image so the light appears to come from the top of the image.

With the help of google earth images we can identify the structural lineament trends (faults, fractures, joints and folds) and the lithologic information and other geomorphological information [8]. Lineament trend lines can created by following the impression of the ridges, valleys and planes of the other geological features by using the add path and specify with geological feature descriptions as shown in fig. 3. By rotating and tilting the google terrains we can easily follow the trend path of the lineaments and other structural features and marked these contacts and stored for future references.

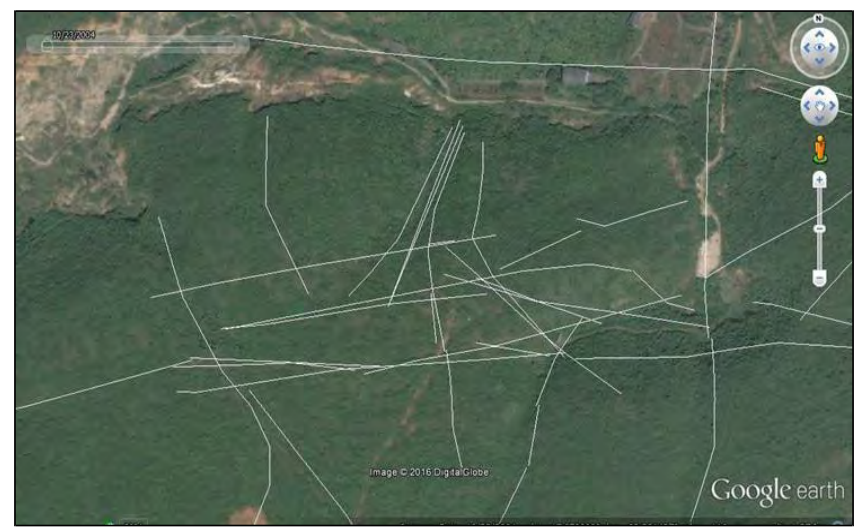

Fig. 3 Identification of lineaments in google earth

\section{B. Detail Investigation Stage}

\section{1) Assign joint orientation/symbols in google earth}

CAD Software SketchUp is used to generate the structural symbols for mapping ground-based structures in $\mathrm{GE}$, and to convert graphic image files of 2D cross sections into 3D Collada object models that are capable of being stretched, oriented and rotated in GE for display in profile view. Excel worksheets are used to generate KML scripts for the structural symbology and well-field visualization. The structure names, geographic coordinates, object orientations and descriptive variables are entered into Excel worksheets that write KML scripts to cell blocks. The script blocks are copied and pasted into ASCII text editors such as MS Notepad.exe, then saved as KML scripts that can be opened in GE.

This application uses Microsoft Excel (Excel) map 2D structural-geological symbols and 3D circles (or ellipses) at specified coordinates (latitude-longitude) in GE. The Excel (2000) workbook contains worksheets for generating geological symbols that have geographic coordinates and structural orientations. The worksheets consist of cell blocks with numeric input, process code, and text output.

The output text block uses the KML form of the XML encoding language. The application is designed for use with geographic-coordinate input (decimal degrees) of longitude (X-coordinate), latitude (Y-coordinate) and altitude (Zcoordinate) in meters. Altitude values of 0 can be used for clamping structures to the ground.

Structural geological coordinates for oriented planes and lines use the dip azimuth $\left(0-359^{\circ}\right)$ and dip/plunge $\left(0-90^{\circ}\right)$ format. Annotation is generated for each symbol or plane using an azimuth/inclination format, (for example a plane with a dip azimuth of $128^{\circ}$ and an inclination of 860 is annotated as123/68).

MS Excel Worksheet for Generating KML Scripts for mapping oriented geological symbols Data can be manually entered into the worksheet input cells, or copied and pasted in blocks from existing ASCII text files, other spreadsheets and database (.dbf) files.

Azimuth, Dip/Plunge, Xscale, Yscale, Zscale, Symbol, Note, and Color must be input. Ordinarily, the Station, Longitude, Latitude, and structural Azimuth and Dip/Plunge are copied from an ASCII text file or station shape file .dbf file. The scripted cells are converted to a KML file by highlighting the cell block, then copy and paste the contents to an ASCII text editor, such as MS Notepad.exe, then within Notepad, save the files as <File $><$ Save As $>$ $<$ Enterthefilename.kml $>$. Then open the saved KML file in GE $<$ File $><$ Open $><$ Thesavedfile.kml $>$.

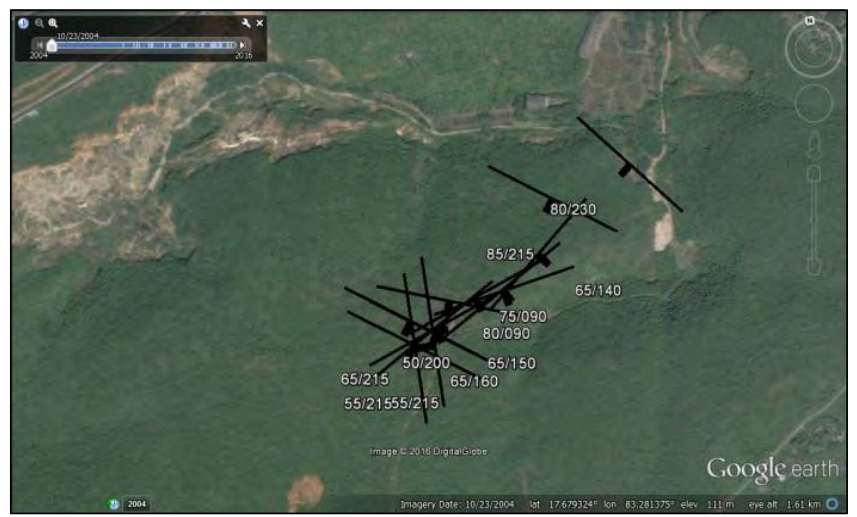

Fig. 4 Assign geologic orientation symbols in google earth

The KML script used to generate the display bedding, 
cleavage, joint, and lineation reading. We can copy and paste this code into an ASCII text editor, save it as a $\mathrm{kml}$ file, and then open it in GE as shown in fig. 4.

\section{2) Development of structural trend map in google earth}

To create a structural trend map we need to lineament trend map which developed in google earth with draw lines to follow the structural lineament using 3D/2D view and rotating google images in different view. For verification and confirmation of these lineament trends we can use the geological surface mapping orientation data (collected during geological site investigation) assign orientation symbols on google earth as shown in fig. 5. After assigning the geological symbols on google earth (geological orientation and features, collected during site investigation) and previously developed structural lineament trends, we can developed the structural lineament trends map on the google earth, and identified and verified the prominent geological features in the project area.

\section{3) Interpretation of lineament trend}

Virtual globes are outstandingly useful for visualizing structural geology, Virtual globes can combine displays of geology and topography, allow rapid changes of scale and view point, and can easily integrate other digital data such as outcrop photographs. Virtual globes are also very effective for teaching structural geology, partly because they give more intuitive views of geology than traditional maps $[9,11]$.

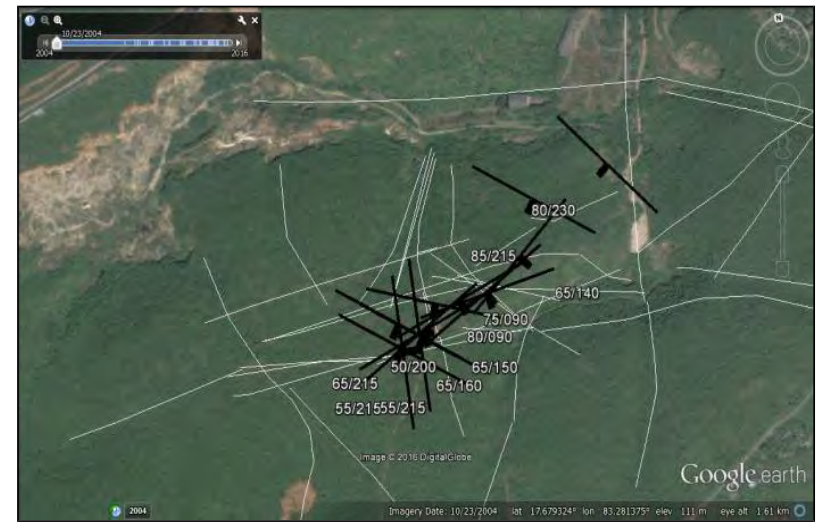

Fig. 5. Geologic orientation symbols and identified lineament trends in google earth

Colour selection should complement the background colour light in the Google Earth image: light colours for dark images and vice versa. Each model can be displayed at a variable height above ground, set by the height parameter. Models that show rectangles emerging from the ground are particularly effective for understanding the relation between topography and geological surfaces. Combinations of colours and symbols can be used to represent different types of structures, rock types or structural domains. When two planar surfaces are plotted at the same locality (e.g. bedding, cleavage), the two symbols intersect each other, making their line of intersection readily visible. The consistency of measurements can be evaluated and used for structural interpretation.

\section{During Construction}

1) Back analysis and validation of the identified lineaments

After development of the structural trend map we need to back analysis and validation of these identified lineaments with the geological structural map which is developed and updated during the construction stage of a project by site Geologist. For back analysis and validation of these structural trend map we need to import these developed google earth images into the auto cad for the purpose of modification and superimposed with structural geological map and comparison.

Overlay Project Layout and Structural Geological Map with Google Image in Auto Cad:

To validation of the structural trend map developed by using google earth, we need to use actual geological data which may provide from structural geological map of the underground rock storage project site in auto cad form, the steps follow to validate lineament trend using google earth is below[12].

- Mark the tunnel entrance or any other identified structures in google earth using placemark tool

- Save/export google image in JPEG/PNG format

- Import/copy above saved image in auto cad

- Open/place project layout on auto cad

- Match the identified structures or tunnel entrances with auto cad drawings (using scaling command), and orient the image with tunnel layout (using rotation command)

- Overlay the image with project layout (fig. 6)

- Import/ copy actual structural geological map and overlay it with project layout

- We can use different layers for different components

- Now we can compare predicted structural trend map with actual structural geological map.

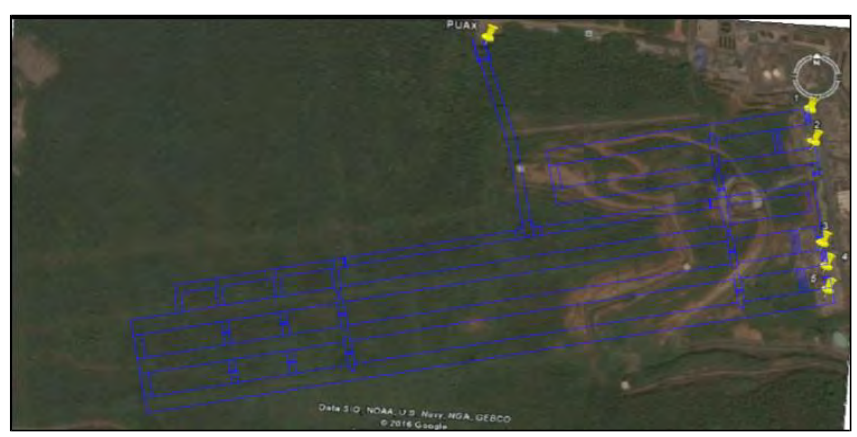

Fig. 6 Google earth image overlay with project layout

Back analysis and validation of lineaments using contour map in SketchUp is the almost same process as like the process of using google earth. In this technique we need to save/export the Sketch Up file into JPEG format. Open the project layout in autocad and then import/copy saved image in auto cad. Match the reference points with layout and scale the image. Orient the image with tunnel alignment, and then open/copy the actual structural geological map with project layout. We can hide and unhide this component using layer on/off and can validate these predicted structural trend map with actual structural geological map. 
Lineaments, as expected, are strongly correlative with structures that have obvious surface expression. When a lineament is perceived, actually a tonal representation of reflectance contrast that is related to variations in vegetation, soils, and topography is seen. These surface characteristics are often influenced by structural features, Such as folds, faults, and joints. More surprising is the coincidence between individual lineaments, as well as lineament zones and lineament areas, and buried structural features. These deep- seated structures and tectonic features include, for example, buried uplifts, buried igneous plugs and salt diapirs, subsurface folds and faults (both thrust and normal faults), strata affected by subtle regional warping, and stratigraphic pinch-outs. Few mechanisms for surface expression of such features are available, yet major subsurface and surface structures in most of the survey region were detected by association with lineaments.

\section{INTERPRETATION OF ACTUAL STRUCTURAL LINEAMENT TREND MAP W.R.T TUNNEL ALIGNMENT}

Geological mapping is evolving from the conventional field survey to the use of google earth techniques. this technology were useful and has shown a great promise for large-scale geological mapping to identified of structural features, such as faults and folds. We can observe lineament trends on the basis of using google earth tools and can interpretation the trends of surface major structural features such as folds, lineaments, fracture zones, and/or fracture traces. As a result, surface structural features have been used to examine any relationship with the tunnel alignment of a project.

Interpretation and analysis of google earth images, integrated with published geological maps, has provided the basis for a re-examination of the structural geology of the area, and has enabled a new interpretation of the tectonic development of the project area to be made. In addition to detecting structural lineament trends a number of important structures can marked and analyse using the imagery, and the resulting maps represent an improvement on existing publications. Tectonic features, particularly folds and faults near the project area can marked, orientation, statistics and rose diagrams for all the interpreted linear features acquired in the study area can prepare and calculate which given as a total distribution and then the totals are broken down by the major elements of the area. We can recognised the lineaments a lot as possible, Their lengths, and average range of spacing between lineaments and the dominant trends of the lineaments and the set of parallel lineament can recognised in the project area. The correlation between surface linear features and subsurface structural orientation can assessed, and the implication of using surface lineament and fracture analysis for underground tunneling in the region discussed. The results can prove the validity and indicate the significance of using surface linear features for inferring underground tunneling in the study area. Fig. 7 shown the predicted lineament trend lines with actual geological structural map and project layout, and a comparison of these predicted and actual map are shown in the fig. 8. For compare the lineament trends identified from google earth tools and data obtained from surface geological mapping and geological mapping during excavation, a rosette plot has been prepared and the rosette plot result as shown in the fig. 9.

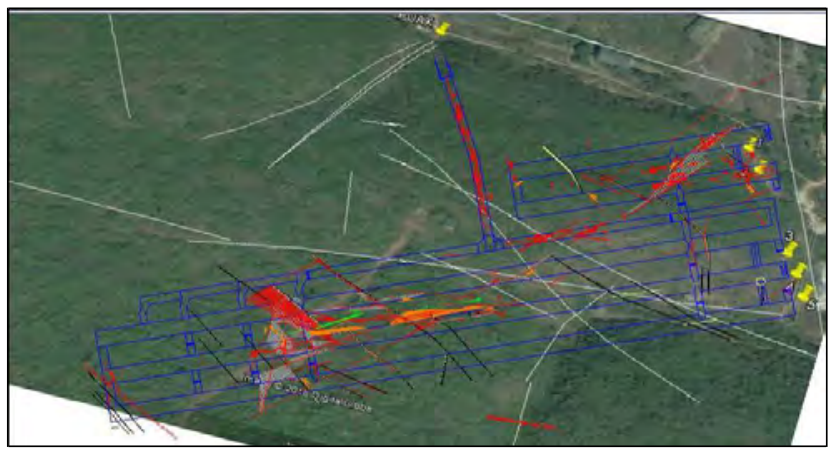

Fig. 7 Google earth image overlay with project layout, predicted lineament trend map and actual structural map

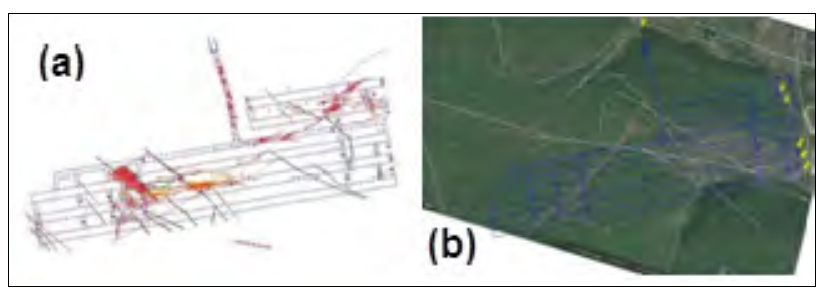

Fig. 8 Comparison of actual and predicted geologic map (a) Actual geologic structural map (b) Predicted Lineament trend map

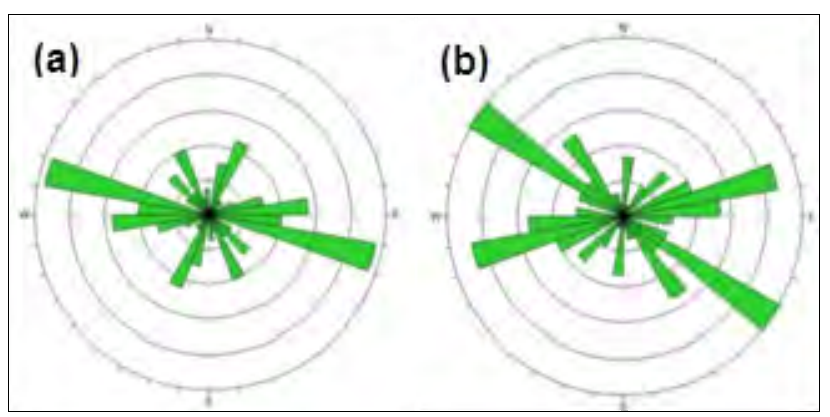

Fig. 9 Comparison of predicted and actual rosette plot (a) Rosette plot of the lineations identified using google earth (b) Rosette plot of joints obtained from mapping

\section{CATEGORIZING THE IDENTIFIED LINEAMENTS AS PER THEIR FEATURES \& PROJECTING THESE FEATURES FOR THE NEXT STAGE OF EXCAVATION}

Each lineament map initially was seen as a nearly undecipherable montage. Instances of probable affinity were recognized when lineaments and structures were geographically convergent; but structural relations of lineaments in other areas could not be predicted, and apparent conflicts with the structural/ tectonic data base could not be resolved. Gradually, however, the lineaments were qualitatively characterized in terms of their relative densities, lengths, and intersection angles (perpendicular, oblique, subparallel, or parallel). This Approach has proved a means of grouping the lineaments on The basis of similar characteristics. Recurring patterns of association were noted among the lineaments, both individually and in combination as lineament zones and areas. Moreover, each type of 
association appears to be correlative with a particular kind of structure. If this conclusion is true, this method of lineament analysis could prove useful for exploration [2,3]. The primary method of classifying lineament patterns was, thus, based on recognition of morphometric similarities without prior resort to genetic interpretations. Whether the resulting classes were consistently correlative with structures throughout the region was determined. If the correlation were consistent, a class became a "model" by which we could extend our interpretations. Each of these lineament models corresponds to a particular kind of structure and to characteristic patterns.

During desk study and pre-investigation stage, identify the possible lineaments using google earth image and google tools (SketchUp) to creating contour of the proposed project site and prepared a predicted lineament trend map of the site for the initial imagination or first step to generalize the geological environment of the proposed project site.

On the basis of predicted lineament trend map, identify the lineament location on the field and perform surface geological mapping of the proposed project site. To confirmation of the geological features and projecting with underground opening need to perform additional investigations. On the basis of verified lineaments and surface geological mapping find out the locations for subsurface investigation and perform geotechnical and geophysical investigation on the project site.

Geological features identified from the coring and major joint orientation find out from the core logging we can categorize these geological features (joint, shear, dykes, fault zones etc.) and on the basis of its orientation we can project these geologic features in the proposed underground openings to prevent any geological related risk.During construction of the approach and other utility tunnels we can apply these predicted structural map for construction and confirmed it with actual structural data obtained during excavation and updated with actual geological data and convert it to actual geological structural map for projecting these features for next stage of excavation. On the basis of predicted lineament trend map and actual structural geological map with the help of geological mapping and core logging, categorized these identified geological features as:

\section{A) Joints}

Joints are fractures without any displacement although they can occur singly, they most frequently occur as joint sets and systems. A joint set is a family of parallel, evenly spaced joints that can be identified through mapping and analysis of the orientations, spacing, and physical properties. A joint system consists of two or more intersecting joint sets. The most prominent joints occur in the most wellconsolidated, lithified, and highly competent rocks.

Three plus random joint set has been identified on the basis of core logging and face mapping data of the project site, the set of joints orientated with different directions and inclinations, strike direction of the major joint set J1 (Foliation/Bedding joints) identified NE-SW with Dip of SE
$650-750$, this joint set is the major joint set of the project site and filled with clay materials and rough, planar joint surface and average joint spacing of 0.2 to $2.0 \mathrm{~m}$. J2 also sub-vertical joint set which trending from NE-SW direction with dip of 650 to $80 \mathrm{o} \mathrm{SE}$ and these joint sets are also clay filled and rough, planar joint surfaces with 0.6 to $2.0 \mathrm{~m}$ joint spacing. J3 is the sub horizontal joint set and trending from NNE to SSW direction with 20o SE dipping, these joints are clay coated and the spacing of 1.0 to $>2.0 \mathrm{~m}$. last set considered as a random joint set trending from SW-NE direction with 650 to $80 \mathrm{o} \mathrm{NW}$ dipping, and the joint spacing of $>2.0 \mathrm{~m}$. below fig. 10 shown the different joint set in a proposed project site as discussed above.

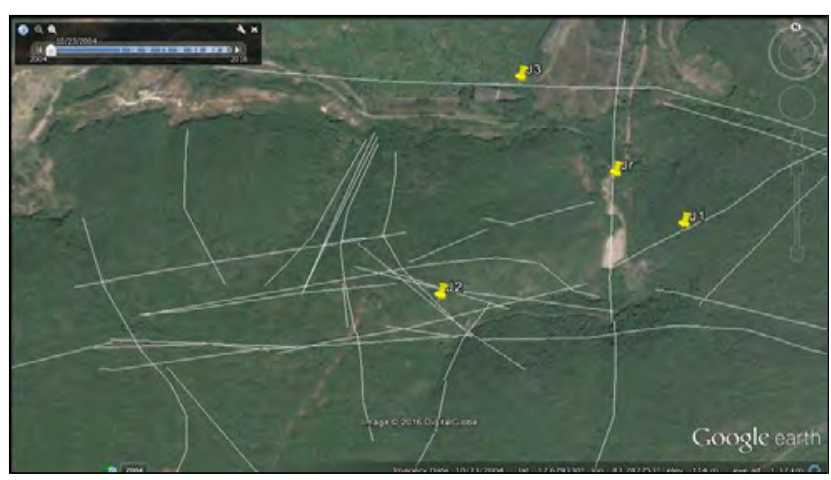

Fig. 10 Different joint sets of the proposed project site

\section{B) Shear/shear zones}

Crustal scale shear zones are fundamental discontinuities that often are the sites of continental accretion, collision extension and intraplate deformation. Such zones may accommodate deformation via simultaneous components of pure and simple shear. The distribution of strain in shear zones may vary spatially and also temporally and pure and simple shear deformation may be partitioned within the shear zone. Once formed shear zones are often zones of weakness and may further deform by reactivation leading to complex polyphaser deformation histories.

The shear joints are filled with clay material and infilled few millimeters to few centimeters and the fractured zones are observed few centimeters to few meters with slickensided planes. And mostly inclined vertical to near vertical angles with parallel to major joint sets. Mostly three set of shear zones are identified on the basis of geological mapping of the opening face and the result of core logging. The shear orientation Sh1 160/65 (variations between 150$170 / 60-80$ notation is dip direction/dip) is the most prominent discontinuity in found at almost areas of the project site. 2 further important shear orientations were observed in the site, Sh2 215/55 (variations between 200235/45-60) and Sh3 090/75 (variations between 090-100/70$80)$. Some fractured zones and slickensided planes are observed in the shear zone areas. Almost all shear planes are steeply dipping at 55 to 80 degree and nearly parallel to the main joint set. Fig.11shown the set of shear zones which are nearly parallel to the major joint set.

\section{C)Fault/ fault zones}

Specific kind of discontinuity associated with movement 
(relative displacement of walls); movement is evident by striations (also called slickenside) and often accompanied by crushing (breccia's, mylonite, gouge, etc.). Three main fault types called, normal fault, reverse fault and strike-slip fault, are defined depending on the movement. Along fault

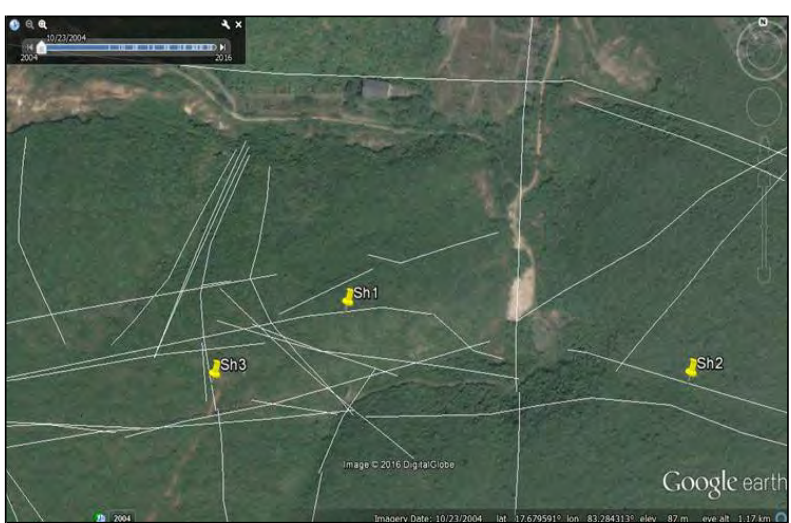

Fig. 11 Shear zones of the proposed project site

walls, rock-mass may be fractured and the intensity and thickness of the fractured zone depend on the geometry and movement(s) of the fault.

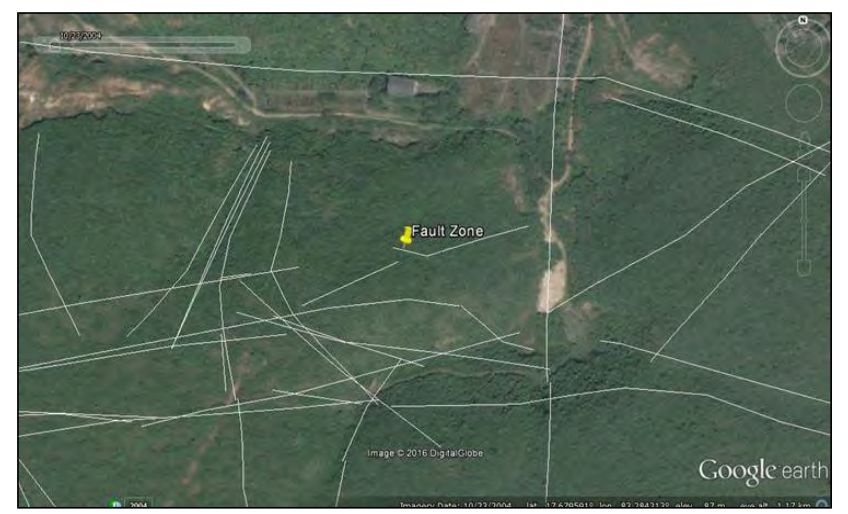

Fig. 12 Fault zone in proposed project site (in Google Image)

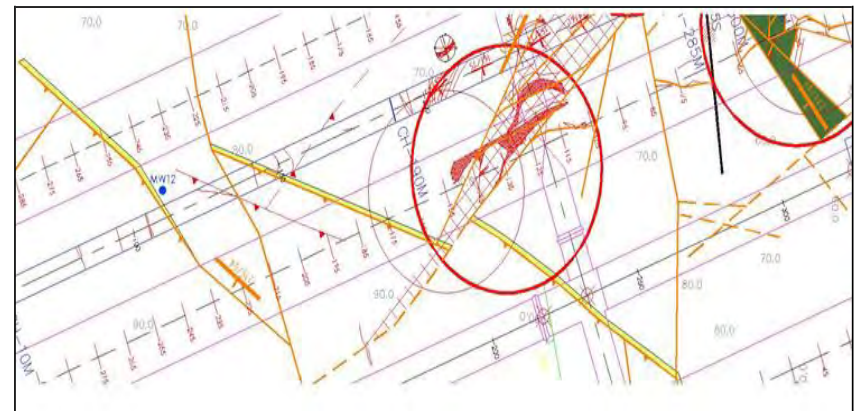

Fig. 13 Fault zone in proposed site (in structural map)

Fault zone observed in the project area which is trending $\mathrm{N} 120^{\circ}-130^{\circ}$ with $70^{\circ}-80^{\circ}$ inclination and near the fault zone gauge materials are filled within fractured rock. This fault plane intersect the joint set of $\mathrm{N} \mathrm{200-215/55-65}$ which is convert to shear joint and due to influencing of this fault zone this joint displaced around $10 \mathrm{~m}$ and after intersection the joint orientation has been changed N230/65. The below fig. 12 and 13 shown the fault zone in the google image and with actual structural map it shown the intersection of fault plane with joint and the displacement of the joint due to influence of fault.

On the basis of rock mass discontinuity characterization we can categorize the geological features and lineaments with different categories as per geological norms. We have categorized the geological features on the result of rock mass discontinuity characterization and the orientations of the lineaments basis from core logging, geological face mapping and surface mapping data. A summary of the categorization of the identified geological features (joints, shear/shear zones \& fault zone) are display in the table 1 and the fig. 14 shown the location and orientation of the categorized identified geological features (identified lineaments) on google image.

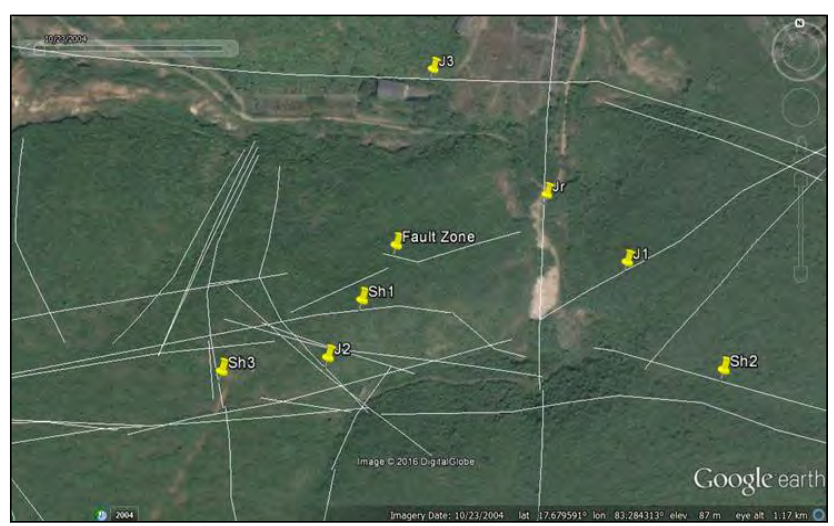

Fig. 14 Joint sets, shear zones and fault zone of the proposes project site

TABLE I. SUMMARY OF THE CATEGORIZATION OF IDENTIFIED GEOLOGICAL FEATURES

\begin{tabular}{|c|c|c|c|}
\hline \multicolumn{4}{|c|}{ Categorization of the identified geological features } \\
\hline Categorization & $\begin{array}{c}\text { Dip } \\
\text { Direction }\end{array}$ & $\begin{array}{c}\text { Dip } \\
\text { Amount }\end{array}$ & Remarks \\
\hline \multicolumn{4}{|l|}{ Joints } \\
\hline $\mathrm{J} 1$ & 165 & $65-75$ & $\begin{array}{l}\text { Rough, planar, } \\
\text { clay-filled, } \\
\text { spacing } 0.2\end{array}$ \\
\hline $\mathrm{J} 2$ & 070 & $65-80$ & $\begin{array}{l}\text { Rough, planar, } \\
\text { clay-filled, spacing } 0.6\end{array}$ \\
\hline $\mathrm{J} 3$ & 010 & 20 & $\begin{array}{l}\text { Rough, planar, clay } \\
\text { coated, spacing } 1.0-\end{array}$ \\
\hline Random Joint & 255 & $65-80$ & $\begin{array}{l}\text { Rough, planar, Clean, } \\
\text { spacing }>2.0 \mathrm{~m}\end{array}$ \\
\hline \multicolumn{4}{|c|}{ Shear Zones } \\
\hline Sh1 & $150-170$ & $60-80$ & \multirow{3}{*}{$\begin{array}{l}\text { Clay filled and } \\
\text { fractured rock mass } \\
\text { mostly near parallel to } \\
\text { the main joint sets }\end{array}$} \\
\hline Sh2 & $200-235$ & $45-60$ & \\
\hline $\operatorname{Sh} 3$ & $090-100$ & $70-80$ & \\
\hline \multicolumn{4}{|c|}{ Fault Zone } \\
\hline & $120-130$ & 80 & $\begin{array}{l}\text { Around } 2.0 \mathrm{~m} \text { thick } \\
\text { fault plane, gauge } \\
\text { material filled within } \\
\text { fractured rock mass, } \\
\text { joint } 210 / 65 \text { displaced } \\
\text { around } 10 \mathrm{~m} \text { due to } \\
\text { fault }\end{array}$ \\
\hline
\end{tabular}




\section{LEARNING FOR BETTER IDENTIFICATION OF GEOLOGIC FEATURES USING GOOGLE TOOLS}

Lineaments are any linear features that can be picked out as lines (appearing as such or evident because of contrasts in terrain or ground cover on either side) in aerial or space imagery. If geological these are usually faults, joints, or boundaries between stratigraphic formations. Other causes of lineaments include roads and railroads, contrast-emphasized contacts between natural or man-made geographic features (e.g., fence lines), or vague "false alarms" caused by unknown (unspecified) factors.

Earth consists of hard rock layers where water is restricted to secondary permeability, and thus to fractures and the weather zones. Structural geology studies, geologic lineaments and their pattern information are essential for better planning and execution of projects to avoid any natural hazards. Satellite images, aerial photographs and digital elevation models will give lineament information.

The identified line features in google earth image may represent natural morphological alignments or those of anthropogenic nature (roads, aqueducts, crops, etc.). Structural discontinuities of rocks and other features related to tectonic activity often results in morphological lineaments (fault scarps, joints, fold axis, etc. These lineaments can be expressed as linear valleys, linear slope breaks or linear ridgelines. Geologic lineament mapping is considered as a very important issue for problem solving in engineering, especially, in site selection for construction (dams, bridges, roads, tunnels etc.), seismic and landslide risk assessment, mineral exploration, hydrogeological research, etc.

On the basis of this document we can use google earth tools for assessing the rock mass stability of the underground opening and predict the geological risk of the proposed project site, and we can use this technique for better interpretation and analysis of the geological data and wish to better ways to identification of the lineaments for future projects. Some points are described below which we have learned from this document and can use for future project to better identification of geological feature: We can use google earth tools at different stage of the project to analyze the geological uncertainty

- During pre-investigation stage of a project identify lineaments properly and use google earth tools (SketchUp) to create contour of the study area and detect the contour edge for better identification

- Identify the location for further investigations (surface and subsurface investigations) on the basis of identified lineaments and surface mapping

- Prepared lineament trend map for proposed project using google earth and CAD tools and predict geological risks for project

- Update predicted lineament trend map with generated data from core logging surface mapping and projecting these geological features with next stage of the excavation

- Assign actual geological features orientations in google earth to compare it with identified lineaments using google earth and analyze the rock mass stability of the underground opening

- Compare and validate prepared predicted data with actual geological features encountered during excavation and update these geological features with actual geological structural map, by validating the initial impression we can improve the system of identifying the important structural features for a projects in that stages.

\section{CONCLUSION}

In this paper a technique has been developed to identify the lineaments using google earth tools for any engineering construction projects. On the basis of this a predictive structural geological lineament trend map has developed and updated it during every stages of construction. For validation of these predicted lineament trends, compare it with actual geological structural map and found mostly same results. This technique can mostly use for initial stage of a project where we can collect the lineaments data of any proposed projects without physical workout to understand the geological uncertainty and risk associated with the project site and analyzing the project layout and better planning of investigations and validated system can be used for the future project around that region.

\section{REFERENCES}

[1] K. Omosanya, G. Mosuro, and A. Akinbodewa, "Integrated mapping of lineament in ago-iwoye SE, SW Nigeria," International journal of scienceand technology volume 1 no.2, february, 2012.

[2] S. Christopher, C. M. Woodruff, Jr., and E. J. Thompson, "lineament analysis and interference of geologic structure - example from the Balcones/Ouachita trend of Texas," Bureau of economic geology, the university of Texas at Austin.

[3] M. Baquero, C. Montes, and G. Bayona, "Lineament analysis in Northern Columbia, South Africa," 5th EARSeL workshop on remote sensing and geology "Surveying the GEOsphere," Waesaw, Poland $19^{\text {th }} 20$ th June, 2014.

[4] P. Prabhu, and B. Rajagopalan, "Mapping of lineaments for groundwater targeting and sustainable water resource management in hard rock hydrogeological environment using RS-GIS," Dr P. Ray (Ed.), InTech, DOI: 10.5772/55702.

[5] G. M. Levis, and S. J. Hampton, "Modeling complex geologic concepts in google sketch-Up: an integrated geoeducation tool," June 11, 2012.

[6] P. H. Karnkowski, and W. Ozimkowski, "Multi-coverage geological interpretation of satellite images: a casse study from selected areas of Poland," JAG, Volume 1 - issue 2 - 1999.

[7] S. Chitransh, "Multi-scale lineament and geological mapping elucidates subsurface and regional techtonic influences in Kuwait," Search and discovery article 30382 (2014).

[8] Y. Vasuki, E. J. Holden, P. Kovesi, and S Micklethwaite, "Semiautomatic mapping of geological structures using UVA-based photogrammetric data: an image analysis approach," Computers \& Geosciences 69 (2014) 22-32.

[9] O. P. Shufeldt, S. J. Whitmeyer, "The new frontier of interactive, digital geologic maps: google earth-based multi level maps of Virginia geology," The geological society of America, 2012.

[10]G. C. Herman, "Structural geology methods and applications for google earth," Google earth geonotes 1.0, G. C. Herman, 03/2012.

[11] S. J. Whitmeyer, J. Nicoletti, J, Madison and G. Declan De Paor, "The digital revolution in geologic mapping," April/May 2010, GSA Today.

[12]T. G. Blenkinsop, "Visualizing structural geology: from excel to google earth," Computer \& Geosciences 45 (2012) 52-56. 